\title{
Quadriceps muscle properties in rheumatoid arthritis: insights about muscle morphology, activation and functional capacity
}

Denise Blum ${ }^{1}$, Rodrigo Rodrigues ${ }^{2,3^{*}} \mathbb{D}$, Jeam Marcel Geremia ${ }^{2}$, Claiton Viegas Brenol ${ }^{1}$, Marco Aurélio Vaz ${ }^{2}$ and Ricardo Machado Xavier ${ }^{1}$

\begin{abstract}
Background: Rheumatoid arthritis (RA) is an inflammatory and chronic autoimmune disease that leads to muscle mass loss and functional capacity impairment, potentiated by physical inactivity. Despite evidences demonstrate neuromuscular impairments in RA patients, aging effects may have masked the results of similar previous studies. The aim of study was to verify (i) the effects of RA on functional capacity and muscle properties in middle-aged patients and (ii) the association between age, clinical characteristics, quadriceps muscle properties and functional capacity.

Methods: Thirty-five RA women and 35 healthy age-matched women were compared with the following outcomes: (i) physical activity level through the International Physical Activity Questionnaire (IPAQ); (ii) timed-up and go (TUG) test; (iii) isometric knee extensor muscular strength; and (iv) vastus lateralis muscle activation and muscle architecture (muscle thickness, pennation angle and fascicle length) during an isometric test. An independent Student t-test and partial correlation (controlled by physical activity levels) were performed, with $p<0.05$.

Results: Compared with healthy women, RA presented (i) lower physical activity level $(-29.4 \% ; p<0.001$ ); (ii) lower isometric knee extensor strength $(-20.5 \% ; p<0.001)$; (iii) lower TUG performance $(-21.7 \% ; p<0.001)$; (iv) smaller muscle thickness $(-23.3 \% ; p<0.001)$ and pennation angle $(-14.1 \% ; p=0.011)$. No differences were observed in muscle activation and fascicle length. Finally, the correlation demonstrated that, with exception of TUG, muscle strength and muscle morphology were not associated with age in RA, differently from healthy participants.
\end{abstract}

Conclusion: Middle-aged RA patients' impairments occurred due to the disease independently of the aging process, except for functional capacity. Physical inactivity may have potentiated these losses.

Keywords: Arthritis, rheumatoid, Quadriceps muscle, Electromyography, Muscular atrophy, Muscle strength

\section{Introduction}

Rheumatoid arthritis (RA) is a chronic autoimmune disease that causes joint inflammation and progressive joint destruction [1]. Its main symptoms are joint pain, morning stiffness and fatigue [2]. In industrialized countries,

\footnotetext{
* Correspondence: rodrigo.esef@gmail.com

¿2aboratório de Pesquisa do Exercício, Universidade Federal do Rio Grande do Sul, Porto Alegre, Brazil

${ }^{3}$ Centro Universitário da Serra Gaúcha, Caxias do Sul, Brazil

Full list of author information is available at the end of the article
}

RA affects $0.5-1 \%$ of adults, with $5-50$ per 100,000 new cases annually. Fifty percent for RA's development risk has been attributed to genetic factors [2]. Moreover, RA patients usually avoid physical activities due to their fear of exacerbating the disease symptoms [3], which contributes to an enhanced pro-inflammatory burden and high level of disease activity [4]. However, regular muscle contraction may suppress pro-inflammatory activity [5], and, consequently, attenuate the disease's activity level.

(c) The Author(s). 2020 Open Access This article is licensed under a Creative Commons Attribution 4.0 International License, which permits use, sharing, adaptation, distribution and reproduction in any medium or format, as long as you give appropriate credit to the original author(s) and the source, provide a link to the Creative Commons licence, and indicate if changes were made. The images or other third party material in this article are included in the article's Creative Commons licence, unless indicated otherwise in a credit line to the material. If material is not included in the article's Creative Commons licence and your intended use is not permitted by statutory regulation or exceeds the permitted use, you will need to obtain permission directly from the copyright holder. To view a copy of this licence, visit http://creativecommons.org/licenses/by/4.0/ 
One of RA's structural manifestations is rheumatoid cachexia that consists of a muscle mass reduction due to an increased muscle protein catabolism induced by inflammatory cytokines [6, 7]. This muscle mass loss generates an impairment in RA patients physical function and functional capacity [8].

Previous studies observed a smaller vastus lateralis (VL) pennation angle, cross-sectional area (CSA) and volume in RA patients compared to healthy subjects $[1,6]$. However, functional capacity impairment $[1,9]$, without changes in knee extensor muscle activity and strength, has been observed [1, 6, 9]. Despite RA's mechanisms are not completely clear, the identification of neuromuscular changes induced by RA is critical in order to create adequate rehabilitation programs able to improve the patients' functional capacity $[1,6,7]$. Previous clinical studies demonstrated a relationship between knee extensor morphological parameters, muscular strength, and functional capacity in knee osteoarthritis [10], cancer [11] and chronic obstructive pulmonary disease (COPD) patients [12].

Although changes in quadriceps morphological parameters were observed in RA patients [1, 6, 9], it is important to note that the contribution of muscle activation parameters to the observed knee extensor muscle strength impairment in RA patients is uncertain $[1,6,13]$. Despite the losses in muscle mass, muscle strength, and functional capacity observed in RA patients in previous studies $[1,6,13]$, their neuromuscular parameters results were probably masked due to aging effects. Similar results to those in RA were observed for strength $[14,15]$, functional capacity [16], VL muscle thickness [17, 18], pennation angle [18] and activation [19] with aging, which are also augmented by physical inactivity [20].

Thus, despite functional and neuromuscular changes were observed in RA patients $[1,6,13]$, the aging effects might have masked the true neuromuscular adaptations due to RA. Based in these observed limitations, the first aim of the present study was to verify the RA impact on quadriceps muscle properties, muscular strength and functional capacity in middle-aged RA women compared with healthy controls, matched by sex and age. In addition, we wanted to verify if there is an association between age, clinical characteristics, muscle parameters and functional capacity in both groups.

\section{Material and methods}

\section{Subjects}

RA's patients that presented functional classes I (able to perform usual activities of daily living, including selfcare, vocational and avocational activities) and II (able to perform usual self-care and vocational activities, but limited in avocational activities), according to the American Rheumatism Association's 1992 revised criteria [21] and at least 3 years of confirmed diagnosis were recruited from the rheumatology service of Hospital de Clínicas de Porto Alegre. Exclusion criteria included the presence of any cardiovascular, neuromuscular and metabolic diseases, inability to walk or flex the knee and knee replacement, pain or swelling in the knee joint. Additionally, juvenile RA patients were also excluded. The recruited RA patients were compared with age and sex matched healthy controls (GC), which were recruited from the local community. A written informed consent was obtained from all participants before starting the experiment. The study was approved by the Hospital Ethical Research Committee (number 09-634) and was conducted respecting the ethical standards of the Declaration of Helsinki General Assembly Meeting (October 2008).

At the lab, participants performed the following evaluations: (i) questionnaires and scales; (ii) body composition measurements; (iii), knee extensor muscle architecture, muscle activation, muscular strength, and (iv) the TimedUp and Go (TUG) test. All neuromuscular parameters were measured on the participants' right limb, based on a previous study [1].

\section{RA disease activity, pain score, physical activity and function}

Disease activity in RA patients was estimated using the composite score of the Disease Activity Score-28 with Erythrocyte Sedimentation Rate (DAS28-ESR). Scores below 2.6 indicated remission, from 2.6 to 3.1 low, from 3.2 to 5.1 moderate, and higher than 5.1 indicated high disease activity [22].

Physical activity level was determined through the International Physical Activity Questionnaire (IPAQ), which captures the activities' intensity performed during leisure time, at work, during domestic tasks and active transport. The sum of all these activities is defined as the total physical activity and was presented in met.min.week [17].

Additionally, the self-assessed physical function was obtained through the Health Assessment Questionnaire (HAQ), which includes questions about the performance on activities of daily living [23]. Also, before any physical test, the pain level was evaluated with a $0-100 \mathrm{~mm}$ visual analogue scale (VAS), where 0 and $100 \mathrm{~mm}$ corresponded to no pain and intolerable pain, respectively.

\section{Functional capacity and knee extensor muscular strength}

The TUG test measures the time for an individual to rise from a chair, walk $3 \mathrm{~m}$ to touch a marker on a wall, turn $180^{\circ}$, return to the chair and sit down [16]. Time was recorded by a stopwatch, and participants were instructed not to use their hands when rising from or sitting back down on the chair.

Maximal knee-extensor muscle strength was measured with a Biodex System 3 dynamometer (Biodex Medical 
Systems, Shirley, NY, USA). Volunteers were positioned on the dynamometer according to the manufacturer's recommendations for knee evaluations, with the hip angle fixed at $85^{\circ}$, knee flexed at $90^{\circ}$ and the trunk, hips and thighs firmly strapped to the apparatus. Subjects performed a warm-up protocol consisting of 10 submaximal knee extension/flexion repetitions at an angular velocity of $90^{\circ} . \mathrm{s}^{-1}$. Next, subjects were instructed to execute the test with the highest possible effort to develop maximal knee extension, and verbal encouragement was provided throughout the test. Three knee extensor isometric tests at $90^{\circ}$ of knee flexion $\left(0^{\circ}=\right.$ full knee extension $)$ were executed, with a 2-min resting period between contractions [24, 25]. The peak torque obtained from these three contractions was normalized to body mass $(\mathrm{Nm} / \mathrm{Kg})$ and used for analysis.

\section{Muscle architecture measurements}

A B-mode ultrasonography system (SSD-4000; Aloka Inc., Tokyo, Japan) with a linear-array probe $(60 \mathrm{~mm}, 7.5 \mathrm{MHz})$ was used to determine VL muscle thickness, pennation angle and fascicle length. The same investigator, with extensive experience in ultrasonography, performed all ultrasound measurements, and high reliability values were obtained in the study [24]. Muscle architecture measurements were obtained with the volunteer seated in the dynamometer, during maximal isometric contraction at $90^{\circ}$ of knee flexion. The images were recorded during all data collection through a DVD and synchronized (Horita Video Stop Watch VS - 50; Horita Co., Inc., California, USA) to the isokinetic dynamometer using a single pulse generator. During synchronization, the button was pressed before the isometric test, sending the pulse sampled on a separate channel of the data collection system, which allowed the identification of the exact time of the isometric peak torque and the corresponding ultrasound images used for data analysis during contraction [26].

Scans were taken at the midpoint between the great trochanter and the femur lateral condyle. The ultrasonography probe was covered with water-soluble transmission gel and oriented parallel to the VL muscle fascicles and perpendicular to the skin. The transducer orientation relative to the longitudinal axis of the thigh was different between subjects due to their individual anatomical characteristics. Probe alignment was considered appropriate when several muscle fascicles could be easily delineated without interruption across the image. Ultrasonography images were digitized and analyzed with Image J software (National Institutes of Health, Bethesda, Maryland).

Muscle thickness was considered the distance between deep and superficial aponeuroses, and was calculated through the mean value of five parallel lines drawn at right angles between the superficial and deep aponeuroses along each ultrasonography image. The best fascicle in each image was used for pennation angle and fascicle length analysis. Pennation angle was calculated as the angle between the muscle fascicle and the deep aponeurosis, whereas fascicle length was measured as the length of the fascicular path between the two aponeuroses. When fascicle length was greater than the probe surface, the fascicle line was extrapolated and calculated through a trigonometric function. This mathematical procedure has been used in several studies involving VL fascicle length evaluations [17, 24] (Fig. 1). After that, fascicle length measurement was normalized and expressed as percent of thigh length (distance between the femur lateral condyle and the great trochanter) [27].

\section{Muscle activation}

An 8-channel EMG system (AMT-8, Bortec Biomedical Ltd., Calgary, Canada) was synchronized with the dynamometer through a Windaq data acquisition system (Dataq Instruments Inc., Ohio, USA), and used to evaluate the VL electrical activity during the isometric kneeextensor test. Skin preparation and electrode positioning for EMG evaluation followed standard procedures [28]. Passive electrodes (Meditrace 100, Kendall, Boca Raton, USA) were positioned in bipolar configuration (interelectrode distance: $2.2 \mathrm{~cm})$ on the VL muscle $(2 / 3$ on the line from the anterior superior iliac spine to the patella's lateral side). A reference electrode was fixed on the tibia's medial surface.

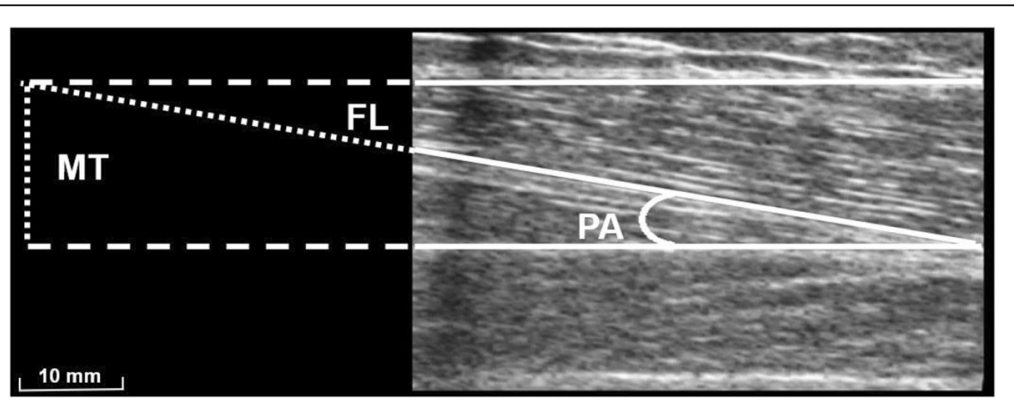

Fig. 1 Ultrasound image showing vastus lateralis muscle architecture parameters: muscle thickness (MT), pennation angle (PA), and estimated fascicle length (FL) 
Raw EMG signals were digitized with a sampling frequency of $2000 \mathrm{~Hz}$ per channel with a DI-720 16 bits analogue-to-digital board (Dataq Instruments Inc., Ohio, USA), and stored for subsequent analysis. Data were exported to MATLAB $^{\circ}$ software (MathWorks Inc., Natick, USA), where they were filtered using a Butterworth band-pass filter, with cut-off frequencies of 20 and $500 \mathrm{~Hz}$. Root mean square (RMS) values were calculated from 1-s segments of the EMG signals obtained from the plateau of the knee-extensor isometric torque. Participants performed an additional knee extensor isometric test at $75^{\circ}$ of knee flexion (optimal angle for maximal knee extensor strength production) [17] to normalize EMG data obtained during the isometric test at $90^{\circ}$ (expressed in percent of maximum).

\section{Statistical analysis}

Sample size was determined from the data obtained in a previous study similar to ours [1] for the variables knee extensor isometric torque, vastus lateralis pennation angle and fascicle length obtained during contraction. Effect size (ES) (Cohen's $d$ ) was calculated for each group (RA patients and healthy subjects) based on mean and SD values. Assuming the ES obtained in each outcome, $\alpha=0.05$ and $\beta=0.95$ in an independent Student ttest, a minimum of 30 participants (15 in each group) were needed for knee isometric torque, 70 participants (35 in each group) for vastus lateralis pennation angle and 28 participants (14 in each group) for vastus lateralis fascicle length. Thus, we adopted the number of 70 participants as the minimum necessary to observe significant differences at the main muscular outcomes used in our study.

Data normality was tested through the Shapiro-Wilk test. Data sphericity was tested by Mauchly test, and Greenhouse-Geisser correction factor was used when the sphericity was violated. An independent Student ttest was used to compare all between-groups outcomes. Effect size was calculated for each paired comparison $(d)$. Cohen's $d$ was interpreted based in the following classification $(<0.2$ : trivial; $>0.2$ : small; $>0.50$ : moderate; $>0.80$ : large) [29].

Moreover, a partial correlation analysis using the physical activity levels as covariant was performed between all neuromuscular outcomes [VL structure and activation, TUG and knee-extensor isometric torque] and age for both groups. Finally, in the RA patients, additional association analysis between neuromuscular outcomes and clinical characteristics (HAQ, DAS28-ESR, disease duration, accumulated and current dose of glucocorticoids and level of pain) were performed. A significance level of $5 \%$ was adopted for all analyses and all statistical procedures were performed in SPSS 20.0.
Table 1 Subjects' characteristics

\begin{tabular}{llll}
\hline & CG $(n=35)$ & RA $(n=35)$ & $p$-value \\
\hline Age (years) & $45.33 \pm 12.50$ & $47.92 \pm 14.37$ & 0.438 \\
Body mass (Kg) & $64.39 \pm 9.84$ & $66.53 \pm 14.97$ & 0.754 \\
Height (m) & $1.62 \pm 0.05$ & $1.60 \pm 0.07$ & 0.634 \\
$\begin{array}{l}\text { Body Mass Index } \\
\text { (kg.m }{ }^{-2} \text { ) }\end{array}$ & $24.53 \pm 4.23$ & $25.81 \pm 5.08$ & 0.249 \\
Pain (VAS) & $0.65 \pm 1.68$ & $3.00 \pm 2.87^{*}$ & $<\mathbf{0 . 0 0 1}$ \\
IPAQ (met.min.week) & $1351.47 \pm 425.12$ & $956.19 \pm 291.09^{*}$ & $<\mathbf{0 . 0 0 1}$ \\
HAQ (pts) & N.A & $0.43 \pm 0.07$ & N.A \\
DAS 28-ESR (pts) & N.A & $3.81 \pm 0.72$ & N.A \\
Disease Duration (years) & N.A & $12.31 \pm 4.32$ & N.A \\
\hline
\end{tabular}

CG Control Group, RA Rheumatoid Arthritis, IPAQ International Physical Activity Questionnaire, VAS Visual Analogue Scale, DAS 28-ESR Disease Activity Scores, $H A Q$ Health Assessment Questionnaire, NA Not Applicable; *difference between-group

\section{Results}

Thirty-five RA women and 35 healthy women (CG) were recruited to participate in the study. RA patients had lower level of physical activity compared to the CG. The Health Assessment Questionnaire (HAQ) score was $0.43 \pm 0.07$ points and the disease activity score (DAS 28 -ESR) was $3.81 \pm 0.72$ points, indicating that most patients displayed a moderate disease activity $(27 / 35,77 \%)$. The RA patients' average disease duration was $12.3 \pm 4.3$ years (Table 1).

All RA patients were under treatment with specific drugs for the disease. Thirty-four patients were taking prednisolone (range $5-30 \mathrm{mg} /$ day, average dose $10.9 \mathrm{mg} /$ day). Thirty-one of them combined this drug with methotrexate (range 10-25 mg/wk., average dose 18.5 $\mathrm{mg} / \mathrm{wk}$ ), and five of them combined prednisolone with other drugs (three using leflunomide, average dose of 20 $\mathrm{mg} / \mathrm{wk}$., and two using hydroxychloroquine, average dose of $240 \mathrm{mg} / \mathrm{wk}$ ). RA patients also displayed higher VAS pain levels compared to controls (Table 1).

Regarding functional capacity, knee-extensor muscular strength and neuromuscular outcomes, RA patients

Table 2 Functional capacity, muscular strength and neuromuscular outcomes data of RA patients and healthy controls

\begin{tabular}{lllll}
\hline Outcome & CG $(n=35)$ & RA $(n=35)$ & $p$-value & ES \\
\hline TUG $(\mathrm{sec})$ & $8.42 \pm 1.37$ & $10.80 \pm 2.72^{*}$ & $<\mathbf{0 . 0 0 1}$ & 1.10 \\
Torque $(\mathrm{Nm} / \mathrm{Kg})$ & $1.94 \pm 0.59$ & $1.40 \pm 0.46^{*}$ & $<\mathbf{0 . 0 0 1}$ & -1.02 \\
VL RMS (\%MIVC) & $92.81 \pm 21.96$ & $99.25 \pm 41.32$ & 0.412 & 0.20 \\
Muscle thickness (cm) & $1.72 \pm 0.31$ & $1.37 \pm 0.34^{*}$ & $<\mathbf{0 . 0 0 1}$ & -1.08 \\
Pennation angle $\left({ }^{\circ}\right)$ & $9.95 \pm 1.81$ & $8.65 \pm 2.36^{*}$ & $\mathbf{0 . 0 1 1}$ & -0.62 \\
Fascicle length (\%) & $25.61 \pm 3.83$ & $25.25 \pm 5.56$ & 0.749 & -0.07
\end{tabular}

CG Control Group, RA Rheumatoid Arthritis Group, ES Effect size, TUG Time-upand go test, $V L$ Vastus lateralis muscle; *difference between-group 

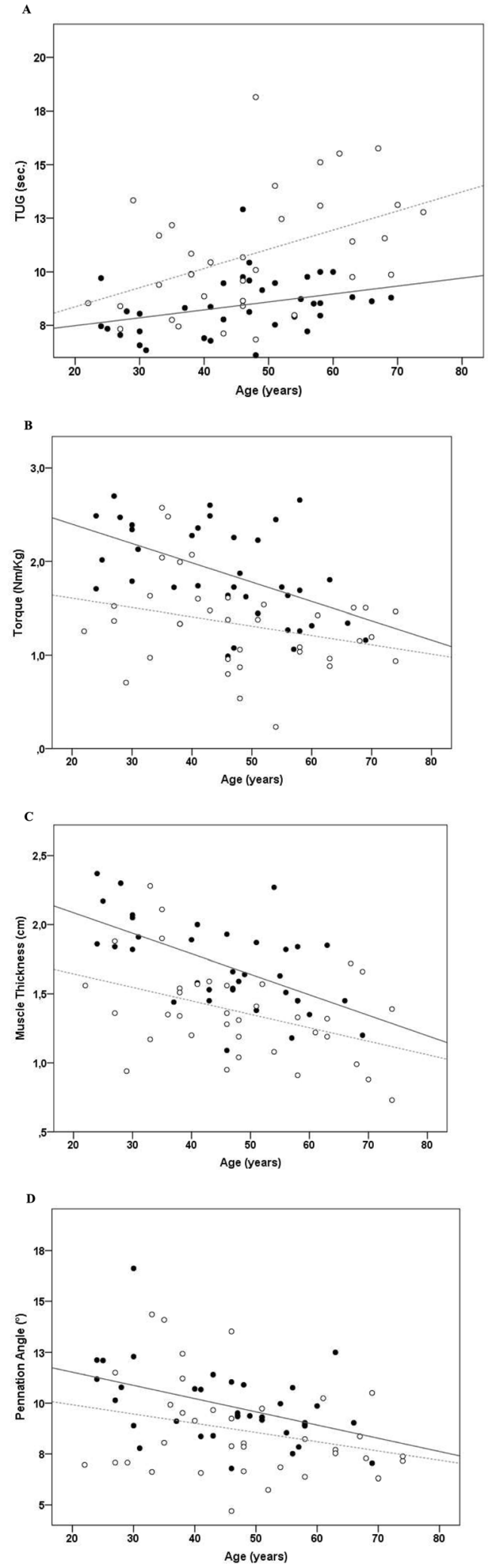

Fig. 2 Partial correlation analysis (controlling by physical activity levels) was significant between TUG and Age in both RA ( $r=0.438$; $p=0.010)$ and $C G(r=0.336 ; p=0.048) \mathbf{a}$, Torque and Age in the CG $(r=-0.498 ; p=0.002)$, but not in RA $(r=-0.317 ; p=0.089)(\mathbf{b})$, Muscle Thickness and Age in the CG $(r=-0.576 ; p<0.001)$, but not in RA ( $r=-0.310 ; p=0.092)$ (c) and Pennation Angle and Age in the CG $(r=-0.462 ; p=0.005)$, but not in RA $(r=-0.260 ; p=0.137)(\mathbf{d})$. Black dots $=C G$; White dots $=$ RA. Solid line $=C$; Dashed line $=$ RA

showed lower TUG performance ( $-21.7 \%$, i.e. longer duration) and knee-extensor isometric torque $(-20.5 \%)$ compared to the CG. RA patients showed smaller VL muscle thickness $(-23.3 \%)$ and pennation angle $(-14.1 \%)$. No between-group differences were observed in the normalized VL fascicle length and activation (Table 2).

The partial correlations (part r) using physical activity levels as a covariant, demonstrated a significant association between: (i) TUG and age in both RA $(r=0.438$; $p=0.010)$ and CG ( $r=0.336$; $p=0.048)$; (ii) knee extensor isometric torque and age in the CG $(r=-0.498 ; p=$ $0.002)$, but not in RA ( $r=-0.317 ; p=0.089$ ); (iii) muscle thickness and age in the CG $(r=-0.576 ; p<0.001)$, but not in RA ( $r=-0.310 ; p=0.092)$ and (iv) pennation angle and age in the CG ( $\mathrm{r}=-0.462 ; p=0.005)$, but not in RA ( $r=-0.260 ; p=0.137)$ (Fig. 2 A-D). No association was observed between age and normalized VL fascicle length and activation in both groups $(p>0.05)$. Additionally, in the RA, no association was observed between clinical characteristics [HAQ, DAS28-ESR, current and accumulated dose of glucocorticoids, disease duration and pain] and functional and neuromuscular outcomes [TUG, torque, VL muscle thickness, pennation angle, fascicle length and activation] $(p>0.05)$ (Table 3$)$.

\section{Discussion}

Our results demonstrated impairment in functional capacity, muscular strength and muscle morphology in RA patients compared to healthy subjects. Except for the TUG, muscle strength and muscle properties were not associated with age in RA, as opposed to healthy participants in which there was an association. These results suggest that the differences observed between RA and CG, except for functional capacity, occurred due to the disease, not to the aging process. The losses in functionality and muscular strength have been commonly explained by changes in neuromuscular outcomes (muscle activity and muscle architecture properties) [11, 30, 31], although muscle activity did not play a role in our case.

Impairment in muscle activation is a possible explanation for muscle strength and functional capacity losses. A previous study [13] observed a significant quadriceps inhibition (8\%) in RA compared to healthy participants, which helped to explain the knee extensor muscular strength impairment. Muscle inhibition mechanisms in 
Table 3 RA patients association between neuromuscular outcomes and clinical characteristics controlled by physical activity level

\begin{tabular}{|c|c|c|c|c|c|c|}
\hline & TUG & Torque & VL RMS & Muscle thickness & Pennation Angle & Fascicle Length \\
\hline \multirow[t]{2}{*}{ Disease duration } & $r=-0.030$ & $r=0.180$ & $r=0.224$ & $r=-0.003$ & $r=-0.310$ & $r=0.318$ \\
\hline & $p=0.879$ & $p=0.328$ & $p=0.244$ & $p=0.988$ & $p=0.102$ & $p=0.093$ \\
\hline \multirow[t]{2}{*}{ DAS28-ESR } & $r=-0.248$ & $r=0.161$ & $r=-0.202$ & $r=0.036$ & $r=-0.126$ & $r=0.161$ \\
\hline & $p=0.194$ & $p=0.404$ & $p=0.294$ & $p=0.851$ & $p=0.515$ & $p=0.404$ \\
\hline \multirow[t]{2}{*}{ HAQ } & $r=-0.119$ & $r=-0.017$ & $r=-0.161$ & $r=-0.013$ & $r=-0.081$ & $r=-0.057$ \\
\hline & $p=0.539$ & $p=0.929$ & $p=0.403$ & $p=0.948$ & $p=0.676$ & $p=0.770$ \\
\hline \multirow[t]{2}{*}{ Current dose of GC } & $r=-0.201$ & $r=0.069$ & $r=-0.104$ & $r=0.131$ & $r=0.092$ & $r=0.018$ \\
\hline & $p=0.296$ & $p=0.721$ & $p=0.592$ & $p=0.498$ & $p=0.634$ & $p=0.927$ \\
\hline \multirow[t]{2}{*}{ Accumulated dose of GC } & $r=-0.172$ & $r=0.125$ & $r=-0.030$ & $r=0.084$ & $r=-0.121$ & $r=0.164$ \\
\hline & $p=0.373$ & $p=0.518$ & $p=0.877$ & $p=0.663$ & $p=0.531$ & $p=0.395$ \\
\hline \multirow[t]{2}{*}{ Pain } & $r=-0.088$ & $r=0.076$ & $r=-0.002$ & $r=0.232$ & $r=0.128$ & $r=0.111$ \\
\hline & $p=0.649$ & $p=0.697$ & $p=0.993$ & $p=0.225$ & $p=0.509$ & $p=0.566$ \\
\hline
\end{tabular}

DAS28-ESR Disease Activity Score-28 with Erythrocyte Sedimentation Rate, HAQ Health Assessment Questionnaire, GC Glucocorticoids

RA are unknown, but abnormal afferent information from articular mechanoreceptors, due to joint damage, effusion and pain, have been proposed to explain the voluntary activation impairment and decreased muscular strength [32]. Our study did not demonstrate an impairment in VL muscle activation during maximal tests, similar to what has been observed in previous studies $[1$, 6]. The absence of pain or swelling in the knee joint of our patients might explain the lack of impairment in $\mathrm{VL}$ muscle activation.

RA patients presented lower muscle thickness and pennation angle during the knee-extensor maximal isometric test compared to the CG. Previous studies observed a decrease in VL physiological cross-sectional area (PCSA) [1] and muscle volume [6] caused by RA, which probably led to a reduction in muscle thickness $[30,31]$ and a smaller force generating capacity [33]. No between-groups differences were observed in fascicle length, agreeing with a previous study [1]. A previous study [34] pointed that an increase in muscle thickness due to training may occur by an increase in pennation angle (addition of in-parallel sarcomeres) or fascicle length (addition of sarcomeres in-series). Thus, the observed smaller muscle thickness in our study was explained by the reduction in pennation angle and not by the fascicle length [35], indicating a parallel loss of sarcomeres due to the rheumatic disease.

Neuromuscular losses observed in our study were also observed in previous studies in patients with chronic disease [10-12, 36]. In RA patients, quadriceps weakness is usually associated with muscle atrophy resulting from the inflammatory process induced by the disease [37], causing proteolytic events, and resulting in cell breakdown and death [38]. In our study, most of the patients displayed a moderate disease activity (77\%), which was not associated with neuromuscular parameters. In addition, pain and disability induced by disease limit the patient's daily living activities [13]. It is interesting to observe that physical inactivity contributes to an enhanced pro-inflammatory condition, and regular muscle contraction may suppress pro-inflammatory activity [5]. Additionally, a higher physical activity level was associated with higher muscle mass [20]. As the disease [39] and physical activity levels [40] are related to poorer muscle performance, and physical inactivity contributes to enhancing pro-inflammatory processes, we believe that our findings are in line with these reports, as the RA group showed lower physical activity levels compared to CG.

Besides physical activity, the use of glucocorticoids is a common strategy to fight the disease and to substantially reduce the rate of erosion progression in RA when used with other anti-rheumatoid drugs [41]. Although the chronic use of glucocorticoids induces muscle atrophy due to increased protein breakdown and decreased protein synthesis [42], this consequence particularly occurs if high doses are used for prolonged periods [43]. We observed that our patients showed an average dose of $10.9 \mathrm{mg} /$ day, being classified as a medium dose (between $7.5-30 \mathrm{mg} /$ day) [44]. The occurrence of myopathy in patients receiving glucocorticoids is rare at low doses [45]. Additionally, the accumulated and current dose of glucocorticoids reported by our patients were not associated with neuromuscular outcomes. Therefore, it is unlikely that our results were related with the use of glucocorticoids. Future research should be directed towards studying the long-term effects of glucocorticoid treatment in RA and its influence on body composition, muscle mass and functional capacity.

To the best of our knowledge, this is the first study to demonstrate a muscle morphology impairment solely related to the rheumatic disease and not to the aging process. The RA patients and healthy subjects age in 
previous studies [1, 6] was quite high (average 59-60 years), indicating a possible aging effect that might have masked the true neuromuscular adaptations due to RA. VL muscle thickness is reduced in the elderly [17, 18], and a muscle mass reduction is considered the major cause for the strength loss [14]. An age-related decline in pennation angle has also been previously reported [18], and is thought to be due to reductions in fiber number and/or fiber diameter that accompany sarcopenia [33]. Our results demonstrated that the neuromuscular adaptations induced by RA occurred independently from the aging process, since, when controlling the physical activity levels, age was not associated with strength and muscle properties, with exception of TUG, differently from what was observed in healthy participants. TUG is a simple test embedding several tasks (stand up from a chair, walk forward, turn around an obstacle, walk back to the chair, and sit down) represented by total time. It is possible that the TUG single components may have presented a different behavior across the aging process [46] and combined with RA. This hypothesis should be further explored.

Decrease in functional capacity and muscular strength could be partially explained by changes in tendon stiffness [47], also observed in RA patients' patellar tendon [9]. The reduction in tendon stiffness is likely due to local and systemic effects of cytokines on the tendon structural characteristics [48]. In addition, the reduction in mechanical overload due to a decrease in physical activity level could potentiate tendon stiffness impairment $[9,47]$. Although we did not measure this outcome, the reduced muscular strength and functional capacity might also be explained by changes in patellar tendon stiffness, since a reduction in tendon stiffness impairs the rate of force development [49] and, consequently, daily living activity (i.e. TUG).

One of the main study limitations was the absence of other tests to evaluate functional capacity, which might have helped us to understand different aspects of functional impairment. Tests such as the 30-s sit-to-stand test and descending stairs might have helped us to identify other functional responses. The lack of dynamic maximal strength measurements are also a limitation, as a low knee extensor muscle shortening velocity decreases the RA patients ability to perform basic activities [50]. Finally, the absence of other quadriceps portions (i.e. vastus medialis and rectus femoris) analysis is also a limitation, since quadriceps muscle neuromuscular parameters have been found as the best dynamic strength predictors [51].

\section{Conclusion}

Middle-aged RA patients presented impairment in functional capacity, quadriceps muscle strength and muscle morphology due to the rheumatic disease, not to the aging process, except for functional capacity. We believe that the combination between physical inactivity and chronic inflammation caused by the disease in RA patients might explain the observed changes. Thus, an increase in the physical activity level may be a safe and effective strategy to minimize the functional losses due to this rheumatic disease.

\section{Abbreviations \\ \%MIVC: Maximal isometric voluntary contraction; CG: Control group; COPD: Chronic obstructive pulmonary disease; CSA: Cross-sectional area; DAS28: Disease activity score; EMG: Electromyography; ES: Effect size; FL: Fascicle length; GC: Glucocorticoids; HAQ: Health Assessment Questionnaire; IPAQ: International physical activity questionnaire; MT: Muscle thickness; PA: Pennation angle; PCSA: Physiological cross-sectional area; RA: Rheumatoid arthritis; RMS: Root mean square; TUG: Timed up and go; VAS: Visual analogic scale; VL: Vastus lateralis}

\section{Acknowledgements}

This work was conducted during a scholarship supported by the International Cooperation Program CAPES/COFECUB at the Federal University of Rio Grande do Sul. Financed by CAPES - Brazilian Federal Agency for Support and Evaluation of Graduate Education within the Ministry of Education of Brazil.

\section{Authors' contributions}

DB: the conception, acquisition of data, analysis and interpretation of data, draft of the article revising it critically for important intellectual content and final approval of the version to be submitted; RR: acquisition of data, analysis and interpretation of data, draft of the article revising it critically for important intellectual content, final approval of the version to be submitted and correspondent author; JMG: acquisition of data, data analysis, critical revision of the article, final approval of the version to be submitted; CVB: critical revision of the article, final approval of the version to be submitted; MAV: interpretation of data, draft of the article revising it critically for important intellectual content, final approval of the version to be submitted: RMX: conception, interpretation of data, draft of the article revising it critically for important intellectual content, final approval of the version to be submitted

\section{Funding}

This work did not have financial support.

Availability of data and materials Not applicable.

\section{Ethics approval and consent to participate}

This study was approved in April 2010 by Clinical Hospital of Porto Alegre Ethical Research Committee (project number 09-634). Also, we confirm that we have read the Journal's position on issues involved in ethical publication and affirm that this report is consistent with those guidelines.

\section{Consent for publication}

Not applicable.

\section{Competing interests}

The authors declare that they have no competing interests.

\section{Author details}

'Serviço de Reumatologia, Hospital de Clínicas de Porto Alegre, Universidade Federal do Rio Grande do Sul, Porto Alegre, Brazil. ${ }^{2}$ Laboratório de Pesquisa do Exercício, Universidade Federal do Rio Grande do Sul, Porto Alegre, Brazil. ${ }^{3}$ Centro Universitário da Serra Gaúcha, Caxias do Sul, Brazil. 
Received: 28 January 2020 Accepted: 30 April 2020 Published online: 19 May 2020

\section{References}

1. Matschke V, Murphy P, Lemmey AB, Maddison P, Thom JM. Skeletal muscle properties in rheumatoid arthritis patients. Med Sci Sports Exerc. 2010; 42(12):2149-55. https://doi.org/10.1249/MSS.0b013e3181e304c3.

2. Scott DL, Wolfe F, Huizinga TW. Rheumatoid arthritis. Lancet. 2010; 376(9746):1094-108. https://doi.org/10.1016/S0140-6736(10)60826-4.

3. Geuskens GA, Burdorf A, Hazes JM. Consequences of rheumatoid arthritis for performance of social roles--a literature review. J Rheumatol. 2007;34(6): $1248-60$.

4. Li Y, Yao L, Liu S, Wu J, Xia L, Shen H, et al. Elevated serum IL-35 levels in rheumatoid arthritis are associated with disease activity. J Investig Med. 2019;67(3):707-10. https://doi.org/10.1136/jim-2018-000814.

5. Bruunsgaard H. Physical activity and modulation of systemic low-level inflammation. J Leukoc Biol. 2005;78(4):819-35. https://doi.org/10.1189/jlb. 0505247.

6. Matschke $V$, Murphy P, Lemmey AB, Maddison PJ, Thom JM. Muscle quality, architecture, and activation in cachectic patients with rheumatoid arthritis. J Rheumatol. 2010;37(2):282-4. https://doi.org/10.3899/jrheum.090584

7. Huffman KM, Jessee R, Andonian B, Davis BN, Narowski R, Huebner JL, et al. Molecular alterations in skeletal muscle in rheumatoid arthritis are related to disease activity, physical inactivity, and disability. Arthritis Res Ther. 2017; 19(1):12. https://doi.org/10.1186/s13075-016-1215-7.

8. de Santana FS, Nascimento Dda C, de Freitas JP, Miranda RF, Muniz LF, Santos Neto L, et al. Assessment of functional capacity in patients with rheumatoid arthritis: implications for recommending exercise. Rev Bras Reumatol. 2014;54(5):378-85. https://doi.org/10.1016/j.rbr.2014.03.021.

9. Matschke $V$, Jones JG, Lemmey AB, Maddison PJ, Thom JM. Patellar tendon properties and lower limb function in rheumatoid arthritis and ankylosing spondylitis versus healthy controls: a cross-sectional study.

ScientificWorldJournal. 2013;2013:514743. https://doi.org/10.1155/2013/ 514743.

10. Gur H, Cakin N. Muscle mass, isokinetic torque, and functional capacity in women with osteoarthritis of the knee. Arch Phys Med Rehabil. 2003;84(10): 1534-41. https://doi.org/10.1016/s0003-9993(03)00288-0.

11. Williams GR, Deal AM, Muss HB, Weinberg MS, Sanoff HK, Nyrop KA, et al. Skeletal muscle measures and physical function in older adults with cancer: sarcopenia or myopenia? Oncotarget. 2017;8(20):33658-65. https://doi.org/ 10.18632/oncotarget.16866

12. Butcher SJ, Pikaluk BJ, Chura RL, Walkner MJ, Farthing JP, Marciniuk DD. Associations between isokinetic muscle strength, high-level functional performance, and physiological parameters in patients with chronic obstructive pulmonary disease. Int J Chron Obstruct Pulmon Dis. 2012;7: 537-42. https://doi.org/10.2147/COPD.S34170.

13. Bearne LM, Scott DL, Hurley MV. Exercise can reverse quadriceps sensorimotor dysfunction that is associated with rheumatoid arthritis without exacerbating disease activity. Rheumatology (Oxford). 2002;41(2): 157-66. https://doi.org/10.1093/rheumatology/41.2.157.

14. Reeves ND, Narici MV, Maganaris CN. In vivo human muscle structure and function: adaptations to resistance training in old age. Exp Physiol. 2004; 89(6):675-89. https://doi.org/10.1113/expphysiol.2004.027797.

15. Suzuki T, Bean JF, Fielding RA. Muscle power of the ankle flexors predicts functional performance in community-dwelling older women. J Am Geriatr Soc. 2001;49(9):1161-7. https://doi.org/10.1046/j.1532-5415.2001.49232.x.

16. Selva Raj I, Bird SR, Shield AJ. Ultrasound measurements of skeletal muscle architecture are associated with strength and functional capacity in older adults. Ultrasound Med Biol. 2017;43(3):586-94. https://doi.org/10.1016/j. ultrasmedbio.2016.11.013.

17. Baroni BM, Geremia JM, Rodrigues R, Borges MK, Jinha A, Herzog W, et al. Functional and morphological adaptations to aging in knee extensor muscles of physically active men. J Appl Biomech. 2013;29(5):535-42. https://doi.org/10.1123/jab.29.5.535.

18. Kubo K, Kanehisa H, Azuma K, Ishizu M, Kuno SY, Okada M, et al. Muscle architectural characteristics in women aged 20-79 years. Med Sci Sports Exerc. 2003;35(1):39-44. https://doi.org/10.1097/00005768-200301000-00007.

19. Piasecki M, Ireland A, Stashuk D, Hamilton-Wright A, Jones DA, MCPhee JS. Age-related neuromuscular changes affecting human vastus lateralis. Physiol. 2016;594(16):4525-36. https://doi.org/10.1113/JP271087.
20. Raguso CA, Kyle U, Kossovsky MP, Roynette C, Paoloni-Giacobino A, Hans D, et al. A 3-year longitudinal study on body composition changes in the elderly: role of physical exercise. Clin Nutr. 2006;25(4):573-80. https://doi. org/10.1016/j.clnu.2005.10.013.

21. Hochberg MC, Chang RW, Dwosh I, Lindsey S, Pincus T, Wolfe F. The American College of Rheumatology 1991 revised criteria for the classification of global functional status in rheumatoid arthritis. Arthritis Rheum. 1992;35(5):498-502. https://doi.org/10.1002/art.1780350502.

22. Prevoo ML. Van 't Hof MA, Kuper HH, van Leeuwen MA, van de Putte LB, van riel PL. modified disease activity scores that include twenty-eight-joint counts. Development and validation in a prospective longitudinal study of patients with rheumatoid arthritis. Arthritis Rheum. 1995;38(1):44-8. https:// doi.org/10.1002/art.1780380107.

23. Fries JF, Spitz PW, Young DY. The dimensions of health outcomes: the health assessment questionnaire, disability and pain scales. J Rheumatol. 1982;9(5):789-93.

24. Baroni BM, Rodrigues R, Franke RA, Geremia JM, Rassier DE, Vaz MA. Time course of neuromuscular adaptations to knee extensor eccentric training. Int J Sports Med. 2013;34(10):904-11. https://doi.org/10.1055/s-00321333263.

25. Rodrigues R, Baroni BM, Pompermayer MG, de Oliveira LR, Geremia JM, Meyer $F$, et al. Effects of acute dehydration on neuromuscular responses of exercised and nonexercised muscles after exercise in the heat. J Strength Cond Res. 2014;28(12):3531-6. https://doi.org/10.1519/JSC. 0000000000000578

26. Geremia JM, Baroni BM, Bobbert MF, Bini RR, Lanferdini FJ, Vaz MA. Effects of high loading by eccentric triceps surae training on Achilles tendon properties in humans. Eur J Appl Physiol. 2018;118(8):1725-36. https://doi. org/10.1007/s00421-018-3904-1.

27. Kumagai K, Abe T, Brechue WF, Ryushi T, Takano S, Mizuno M. Sprint performance is related to muscle fascicle length in male $100-\mathrm{m}$ sprinters. J Appl Physiol (1985). 2000;88(3):811-6. https://doi.org/10.1152/ jappl.2000.88.3.811.

28. SENIAM. Surface ElectroMyoGraphy for the Non-Invasive Assessment of Muscles. Available in < http://www.seniam.org/2017> [Accessed in April 2012].

29. Cohen, J. Statistical Power Analysis for the Behavioral Sciences (2nd ed.). Hillsdale: Lawrence Erlbaum Associates, Publishers;1988.

30. de Boer MD, Seynnes OR, di Prampero PE, Pisot R, Mekjavic IB, Biolo G, et al. Effect of 5 weeks horizontal bed rest on human muscle thickness and architecture of weight bearing and non-weight bearing muscles. Eur J Appl Physiol. 2008;104(2):401-7. https://doi.org/10.1007/s00421-008-0703-0.

31. Fitts RH, Riley DR, Widrick JJ. Functional and structural adaptations of skeletal muscle to microgravity. J Exp Biol. 2001;204(Pt 18):3201-8.

32. Palmieri-Smith RM, Villwock M, Downie B, Hecht G, Zernicke R. Pain and effusion and quadriceps activation and strength. J Athl Train. 2013;48(2): 186-91. https://doi.org/10.4085/1062-6050-48.2.10.

33. Narici MV, Maganaris CN, Reeves ND, Capodaglio P. Effect of aging on human muscle architecture. J Appl Physiol (1985). 2003;95(6):2229-34. https://doi.org/10.1152/japplphysiol.00433.2003.

34. Franchi MV, Reeves ND, Narici MV. Skeletal Muscle Remodeling in Response to Eccentric vs. Concentric Loading: Morphological, Molecular, and Metabolic Adaptations. Front Physiol. 2017;8:447. https://doi.org/10.3389/ fphys.2017.00447.

35. Narici M, Cerretelli P. Changes in human muscle architecture in disuseatrophy evaluated by ultrasound imaging. J Gravit Physiol. 1998;5(1):P73-4

36. Mesquita R, Wilke S, Smid DE, Janssen DJ, Franssen FM, Probst VS, et al. Measurement properties of the timed up \& go test in patients with COPD. Chron Respir Dis. 2016;13(4):344-52. https://doi.org/10.1177/ 1479972316647178.

37. Roth SM, Metter EJ, Ling S, Ferrucci L. Inflammatory factors in age-related muscle wasting. Curr Opin Rheumatol. 2006;18(6):625-30. https://doi.org/10. 1097/01.bor.0000245722.10136.6d.

38. Narici MV, Maganaris CN. Adaptability of elderly human muscles and tendons to increased loading. J Anat. 2006;208(4):433-43. https://doi.org/10. 1111/j.1469-7580.2006.00548.x.

39. Uutela $\mathrm{Tl}$, Kautiainen $\mathrm{HJ}$, Hakkinen $\mathrm{AH}$. Decreasing muscle performance associated with increasing disease activity in patients with rheumatoid arthritis. PLoS One. 2018;13(4):e0194917. https://doi.org/10.1371/journal. pone.0194917.

40. Vardar-Yagli N, Sener G, Saglam M, Calik-Kutukcu E, Arikan H, Inal-Ince D, et al. Associations among physical activity, comorbidity, functional capacity, 
peripheral muscle strength and depression in breast cancer survivors. Asian Pac J Cancer Prev. 2015;16(2):585-9. https://doi.org/10.7314/apjcp. 2015.16.2.585.

41. Kirwan JR, Bijlsma JW, Boers M, Shea BJ. Effects of glucocorticoids on radiological progression in rheumatoid arthritis. Cochrane Database Syst Rev. 2007;1:CD006356. https://doi.org/10.1002/14651858.CD006356.

42. Schakman O, Kalista S, Barbe C, Loumaye A, Thissen JP. Glucocorticoidinduced skeletal muscle atrophy. Int J Biochem Cell Biol. 2013;45(10):216372. https://doi.org/10.1016/j.biocel.2013.05.036

43. McKay LIC, J.A. Physiologic and pharmacologic effects of corticosteroids. In: Kufe DWPR, Weichselbaum RR, editors. Holland-Frei Cancer Medicine, $6^{\text {th }}$ edition, Hamilton (ON): BC Decker 2003.

44. Buttgereit F, da Silva JA, Boers M, Burmester GR, Cutolo M, Jacobs J, et al. Standardised nomenclature for glucocorticoid dosages and glucocorticoid treatment regimens: current questions and tentative answers in rheumatology. Ann Rheum Dis. 2002;61 (8):718-22. https://doi.org/10.1136/ ard.61.8.718

45. McDonough AK, Curtis JR, Saag KG. The epidemiology of glucocorticoidassociated adverse events. Curr Opin Rheumatol. 2008;20(2):131-7. https:// doi.org/10.1097/BOR.0b013e3282f51031.

46. Mangano GRA, Valle MS, Casabona A, Vagnini A, Cioni M. Age-Related Changes in Mobility Evaluated by the Timed Up and Go Test Instrumented through a Single Sensor. Sensors (Basel). 2020;20(3):E719. https://doi.org/10 3390/s20030719.

47. Geremia JM, Bobbert MF, Casa Nova M, Ott RD, Lemos Fde A, Lupion Rde $\mathrm{O}$, et al. The structural and mechanical properties of the Achilles tendon 2 years after surgical repair. Clin Biomech (Bristol, Avon). 2015;30(5):485-92. https://doi.org/10.1016/j.clinbiomech.2015.03.005.

48. Jain A, Nanchahal J, Troeberg L, Green P, Brennan F. Production of cytokines, vascular endothelial growth factor, matrix metalloproteinases, and tissue inhibitor of metalloproteinases 1 by tenosynovium demonstrates its potential for tendon destruction in rheumatoid arthritis. Arthritis Rheum. 2001;44(8):1754-60. https://doi.org/10.1002/1529-0131(200108)44:8<1754:.: AID-ART310>3.0.CO;2-8.

49. Bojsen-Moller J, Magnusson SP, Rasmussen LR, Kjaer M, Aagaard P. Muscle performance during maximal isometric and dynamic contractions is influenced by the stiffness of the tendinous structures. J Appl Physiol (1985). 2005;99(3):986-94. https://doi.org/10.1152/japplphysiol.01305.2004.

50. Sayers SP, Guralnik JM, Thombs LA, Fielding RA. Effect of leg muscle contraction velocity on functional performance in older men and women. J Am Geriatr Soc. 2005;53(3):467-71. https://doi.org/10.1111/j. 1532-5415.2005.53166.x

51. Trezise J, Blazevich AJ. Anatomical and neuromuscular determinants of strength change in previously untrained men following heavy strength training. Front Physiol. 2019;10:1001. https://doi.org/10.3389/ fphys.2019.01001.

\section{Publisher's Note}

Springer Nature remains neutral with regard to jurisdictional claims in published maps and institutional affiliations.

Ready to submit your research? Choose BMC and benefit from:

- fast, convenient online submission

- thorough peer review by experienced researchers in your field

- rapid publication on acceptance

- support for research data, including large and complex data types

- gold Open Access which fosters wider collaboration and increased citations

- maximum visibility for your research: over $100 \mathrm{M}$ website views per year

At $\mathrm{BMC}$, research is always in progress.

Learn more biomedcentral.com/submissions 